\title{
Influence of Major on Vocational College Students' Use of Language Learning Strategies
}

\section{Ouchun Ouyang}

Jiangxi University of Science and Technology, Nanchang, Jiangxi, China

Keywords: LLS (language learning strategies), vocational college students, major

\begin{abstract}
The use of language learning strategies(LLS) by a group of vocational college students in a Chinese college was investigated in this research. The focus was to look at how the major affects the use of LLS among vocational college students who learn English as a foreign language(EFL). The vocational college students should be trained more in the use of LLS. The teachers should also realize that students might use different LLS from different majors.
\end{abstract}

\section{Introduction}

Since the early 1970s, research has been concerned with the field of foreign language teaching and learning which has shifted from methods of teaching to learner characteristics and their influence on the process of acquiring a foreign language. Researchers realize that focusing research on teaching methods alone cannot draw on the latest achievements in the relevant fields, nor can it cover all the various factors (Stern,1983, cited in Rao, 2005). More and more teachers and researchers have initiated research on the learners. They have conducted lots of research focusing on how such factors as language proficiency, motivation, gender, age, cultural background, career orientation, and language learning styles affect students' choice of LLS (Goh \& Kwah, 1997; Wharton, 2000; Rahimi, 2008; Zare,2012; Zha Dehua,2016; Gu Shimin, 2017). The current study emphasizes on the effect of different majors on vocational college students' use of LLS.

\section{Literature Review}

\subsection{Classification of Language Learning Strategy(LLS)}

Since the mid-1970s, researchers and teachers have developed many classification systems or taxonomies (Oxford, 1992). Ellis (1999) mentioned that the most comprehensive classification of LLS to date might be provided by Oxford.

According to the relationship between language materials and learning strategies, Oxford (1992) divided learning strategies into two kinds: direct and indirect strategies. Direct strategies include: memory strategies, compensation strategies, and cognitive strategies. Indirect strategies include: affective strategies, social strategies, and metacognitive strategies.

\subsection{Study on major and language learning strategies}

Compared with other variables, academic major has received less attention in research on the use of learning strategies. However, several studies have shown that major influences choice of LLS. In Chamot et al.'s (1987, cited in Rao 2005) research, it showed that university major had a statistically significant influence on choice of LLS. Study by Oxford and Nyikos' (1989, cited in Rao 2005) also showed similar results.

A research $(\mathrm{Gu}, 2002)$ on vocabulary learning strategies of Chinese EFL learners, however, seemed to contradict this general tendency. In Gu's (2002, cited in Rao 2005) study, academic major was proved to be a less potent background factor in affecting students' LLS use.

Although limited in number, the studies above show that academic major has a strong effect on selection of LLS. The difference in use of LLS between various academic majors indicates that 
different academic majors may result in different motivations and methods to learn a language, which will influence the use of LLS as well.

\section{The Study}

\subsection{Research Questions}

This research was designed to answer the following two questions according to the research objectives: (1) What are vocational college students' general patterns of overall strategy use and use of the six strategy categories? (2) Are there any significant differences in terms of use of the six strategy categories and overall strategy by major?

\subsection{Subjects}

One hundred first-year vocational college students from different majors in a vocational college in Jiangxi province of China were selected in the study. The final sample consisted of 96 vocational college (male 44, $45.8 \%$; female 52, 54.2\%), after 4 students were rejected because of the missing values. The subjects were divided into social science students and science students based on their major field of study (Table 1).

Table 1: Distribution of subjects by major

\begin{tabular}{llll}
\hline Social science students & \multicolumn{3}{c}{ Science students } \\
\hline Chinese literature & 20 & Physics & 18 \\
Tourism management & 19 & Chemistry & 16 \\
Politics and law & 11 & Computer & 12 \\
\hline $\mathrm{N}=50(52.1 \%)$ & & $\mathrm{N}=46(47.9 \%)$ & \\
\hline
\end{tabular}

\subsection{Instruments}

In choosing the questionnaire for this study, the Strategy Inventory for Language Learning (SILL, version 7.0, designed by Oxford) was employed. Oxford's 50-items Strategy Inventory for Language Learning is based on Oxford's classification system in which strategies are included into six categories, each represented by a number of individual strategies. They are Memory strategies (items 1-9); Cognitive strategies (items 10-23); Compensation strategies (items 24-29); Metacognitive strategies (items 30-38); Affective strategies (items 39-44) and Social strategies (items 45-50).

\subsection{Data collection}

In April, 2017, the questionnaires were sent to 100 vocational college students in a vocational college in Jiangxi province. The questionnaire administration took about twenty minutes for each class. After the data were collected, each questionnaire was individually examined and coded for statistical analysis in order to answer the research questions.

\subsection{Data analysis}

To analyze the data, the Statistical Package for the Social Sciences (SPSS, version 19.0) was employed. Descriptive statistics such as means, standard deviations were collected for the SILL results through the SPSS statistical package. In order to get the significance in the study, the standard of $\mathrm{p}<.05$ was employed which means that a result was considered statistically significant if it could have occurred by chance fewer than 5 times out of 100 .

\section{Results and Discussions}

Results and discussions for question one: What are vocational college students' general patterns of overall strategy use and use of the six strategy categories? 
Table 2: Means and standard deviations indicating strategy use of the whole sample

\begin{tabular}{lcc}
\hline $\begin{array}{l}\text { Strategy category } \\
\text { (most used to least used) }\end{array}$ & \multicolumn{1}{c}{ Mean } & Standard deviation \\
\hline Memory & 2.896 & .712 \\
Compensation & 2.845 & .703 \\
Metacognitive & 2.837 & .602 \\
Cognitive & 2.751 & .750 \\
Social & 2.607 & .568 \\
Affective & 2.489 & .467 \\
Overall total & 2.718 & .413 \\
\hline
\end{tabular}

This study showed that memorization was the most frequently used strategy among the 96 vocational college students. This indicated that the students spent significantly more time storing and recalling new information than regulating and managing their learning, just like when they studied in high school. This result contradicted with studies by Lan and Oxford (2003), and Goh and Kwah (1997), but it was consistent with memorization strategies accounts of the learning strategies of Chinese learners.

As we can see from Table 2, in addition to memory strategies, the vocational college students reported using compensation strategies more frequently than other strategies. Riazi and Rahimi (2008) put forward that high employment of compensation strategy often features the language learners struggle against low language competence. This is quite natural and logical in an EFL context like mainland China, where the students do not expose enough to the target language and therefore, they have to resort to their strategic competence to compensate for any linguistic deficiency.

Metacogintive strategies were also found to be popular among the subjects. The reason why the Chinese EFL learners employed metacognitive strategies so frequently might be the fact that China is an EFL context. Therefore language learners did not have much exposure to the target language to pick it up unconsciously. The language learners can compensate for this deficiency through conscious attention, and maybe that is why metacognitive strategies were used at such a high level.

In the current study, cognitive strategies were employed in the middle of the hierarchy of LLS and were used at a medium level.

Social strategies were the second least frequently employed by the vocational college students. As is known to all that these strategies are often employed in the situations where the learners have a lot of opportunity to use the language or have access to speaking with the native speakers. This can justify the scant employment of these strategies of social strategy.

Affective strategies were found to be the least frequent used among the subjects of this study. These findings were consistent with those of similar studies (except Rao' study, 2005). For instance, Park (1997) reported that affective strategies were among the least frequently used strategies.

Overall, the results of the current study are very much similar as that in most studies, except other EFL studies (e.g. Park,1997; Wharton,2000; Peacock and Ho,2003.). Affective strategies were the last or the last two strategy categories just like in this study, affective strategies appeared in the bottom of the hierarchy of strategies.

Results and discussions for question two: Are there any significant differences in terms of overall strategy use and use of the six strategy categories by major?

For each of the six strategies categories, the significant difference was all in favour of social science vocational college students. The results were consistent with a majority of studies on LLS which have reported that social science learners use learning strategies more frequently than science college students (Oxford and Nyikos, 1989; Peacock and Ho,2003; Rao,2005). The main cause of the significant differences in strategy employment seemed to be their different preferred ways of career interests, learning, and curriculum.

Firstly, the students' interest in English is related with their individual careers. Most of the social science vocational college students would choose career which had a strong connection with languages after graduation. Therefore, memorization, and mechanical practice in language learning, which were suitable with social science learners, made science vocational college students feel tired 
and bored.

Table 3: Strategies categories showing significant differences by major with two-way ANOVA

\begin{tabular}{|l|l|l|l|l|}
\hline \multirow{2}{*}{$\begin{array}{l}\text { Strategy } \\
\text { category }\end{array}$} & \multicolumn{2}{|c|}{ Major } & Significant differences \\
\cline { 2 - 5 } & $\begin{array}{l}\text { Social } \\
\text { science }\end{array}$ & science & Pown by ANOVA & $\begin{array}{l}\text { Post hoc test result: Specific } \\
\text { comparisons where significant } \\
\text { difference arose }\end{array}$ \\
\hline memory & 2.97 & 2.78 & $\mathrm{p}=.026$ & SO $>\mathrm{S}$ \\
\hline cognitive & 2.79 & 2.70 & n.s. & \\
\hline compensation & 2.89 & 2.79 & n.s. & \\
\hline metacognitive & 2.88 & 2.80 & n.s. & $\mathrm{SO}>\mathrm{S}$ \\
\hline affective & 2.53 & 2.38 & $\mathrm{p}=.002$ & $\mathrm{SO}>\mathrm{S}$ \\
\hline social & 2.71 & 2.52 & $\mathrm{p}=.011$ & \\
\hline
\end{tabular}

a Significance : $*=\mathrm{p}<.05 \quad * *=\mathrm{p}<.01 \quad * * *=\mathrm{p}<.005 * * * *=\mathrm{p}<.001$

b $\mathrm{SO}=$ Social science, $\mathrm{S}=$ Science .

Secondly, the students' preferred ways of learning influence their use of LLS. According to Biggs (1993, cited in Rao, 2005), students taking part in the learning environment are usually equipped with their own preference. It could also tend to illustrate why the science vocational college students were less flexible in choosing LLS, whereas the social science vocational college students could adapt to diverse types of study tasks by choosing appropriate LLS.

Finally, the strategic differences showed by the two groups of vocational college students might stem from curriculum in the college. A student's learning process depends greatly on the teaching context, in which curriculum is one of the main factors.

\section{Implications}

Students should be aware of the crucial significance of use of LLS. Students with different learning styles usually choose strategies which reflect their own style preferences. As for teachers, it is really significant for them to realize that some strategies may be more suitable to some language learners than to others. The more teachers know about such factors, the more readily the teacher can acquire the nature of individual differences in language teaching.

There are a lot of factors tend to explain individual differences in learners' choosing strategy. Language learners with different language proficiency, gender, learning style and types of motivation tend to choose different kinds of strategies, though not investigated in current study.

Finally, as for learners including vocational college students, the curriculum seemed to be more favourable for social science students than for science students in English study. The former enjoyed the stronger interest and more advantages in learning English, which enabled them to use LLS with greater frequency than the science students.

\section{Acknowledgement}

Chinese foreign language teaching reform for vocational college in 2016: "The Empirical Study of Cooperative, Autonomous, and Inquiry Foreign Language Teaching Mode in Vocational College"(GZWYJXGG-78); Social science study of Ganzhou city in 2016: "The Strategy of Translating Geological and Mining Materials of Ganzhou into English from Dynamic Adaptation Perspective"(16189).

\section{References}

[1] Ellis, R. 2010. Understanding Second Language Acquisition[M]. Shanghai: Shanghai Foreign 


\section{Education Press.}

[2] Ehrman, M., and Oxford, R. (1989). Effects of sex differences, career choice, and psychological type on adult language learning strategies[J]. The Modern Language Journal,73:1-13.

[3] Gu Shimin (2017): Review and Introspection: Language Learning Strategy Research of China[J]. Computer-assisted Foreign Language Education, 4:84-90.

[4] Gu, Y. (2002). Gender, academic major, and vocabulary learning strategies of Chinese EFL learners[J]. RELC Journal,33:35-54.

[5] Lan, R., and Oxford, R. (2003). Language learning strategy profiles of elementary school students in Taiwan [J]. International Review of Applied Linguistics and Language Teaching,41:339-379.

[6] Li Yu. (2006). A survey of language learning strategies used by elementary school students[J]. CELEA Journal,2:71-77.

[7] Oxford, R. (1992). Second language research on individual differences[J]. Annual Review of Applied Linguistics,13:188-205.

[8] Park, G. (1997). Language learning strategies and English proficiency in Korean university students[J]. Foreign Language Annals,30:211-221.

[9] Peacock, M., and Ho, B. (2003). Student language learning strategies across eight disciplines[J]. International Journal of Applied Linguistics,13:179-200.

[10] Rao Zhenhui. (2005). Gender, Academic Major, and Chinese Students: Use of Language Learning Strategies: Social and Educational Perspectives[J]. The Journal of Asia TEFL, 2:115-138.

[11] Rahimi, and Riazi, (2008). An investigation into the factors affecting the use of language learning strategies by Persian EFL learners [J]. CJAL, 11 (2), 31-60.

[12] Wharton, G. (2000). Language learning strategy use of bilingual foreign language learners in Singapore[J]. Language Learning,50:203-243.

[13] Zare, P. (2012). Language learning strategies among EFL/ESL learners: A review of literature [J]. International Journal of Humanities and Social Science, 5: 162-169.

[14] Zha Dehua (2016). Comprehensive Study on Good College English Learners' Learning Strategy[J]. Foreign Language World, 4:66-72. 